\title{
Sitagliptin ameliorates diabetic nephropathy by blocking TGF-ß1/Smad signaling pathway
}

\author{
DONGDONG WANG ${ }^{1,2^{*}}$, GUANYING ZHANG $^{1 *}$, XIAO $\mathrm{CHEN}^{3 *}$, TONG WEI $^{1}$, \\ CHENXU LIU ${ }^{1}$, CHUN CHEN $^{1}$, YINHAN GONG ${ }^{1}$ and QUNLI WEI ${ }^{1}$ \\ ${ }^{1}$ Jiangsu Key Laboratory of New Drug Research and Clinical Pharmacy, Xuzhou Medical University, Xuzhou, Jiangsu 221004; \\ ${ }^{2}$ Department of Pharmacy, Children's Hospital of Fudan University, Shanghai 201102; ${ }^{3}$ Department of Pharmacy, \\ The People's Hospital of Jiangyin, Jiangyin, Jiangsu 214400, P.R. China
}

Received November 13, 2016; Accepted February 2, 2018

DOI: $10.3892 /$ ijmm.2018.3504

\begin{abstract}
Diabetic nephropathy (DN) is the leading cause of end-stage failure of the kidney, but the efficacy of current strategies available for the prevention of DN remains unsatisfactory. The purpose of this study was to assess whether sitagliptin (SIT) has therapeutic potential for prevention of DN and to investigate its possible mechanism. The effects of SIT on DN were investigated in rats with type 2 diabetes mellitus (T2DM) and rat mesangial cells (MCs) induced by high glucose. T2DM rats were administered at a dose of $10 \mathrm{mg} / \mathrm{kg}$ SIT. The kidney index, $24 \mathrm{~h}$ urinary protein, blood urea nitrogen (BUN), serum creatinine $(\mathrm{Cr})$, accumulation of glycogen and collagens were investigated by different methods. MCs were administered with SIT at doses of $0.1,1$ and $10 \mu \mathrm{mol} / \mathrm{ml}$. The possible mechanism of SIT on protection of diabetic kidney injury was examined by expression of transforming growth factor- $\beta 1$ (TGF- $\beta 1$ )/Smad pathway. The results showed that the SIT-treated diabetic rats significantly reduced diabetic kidney injury by inhibiting the kidney index and attenuating $24 \mathrm{~h}$ urinary protein, reducing BUN and serum creatinine, inhibiting progressive renal fibrosis and increassing extracellular matrix including collagen IV and fibronectin. Further studies showed that inhibition of renal fibrosis in SIT-treated diabetic rats and MCs were associated with rebalancing of TGF- $\beta 1 /$ Smad pathway. Sitagliptin may be a potent agent for preventing the progression of DN through inhabiting TGF- $\beta 1 /$ Smad-mediated renal fibrosis.
\end{abstract}

Correspondence to: Professor Qunli Wei or Professor Yinhan Gong, Jiangsu Key Laboratory of New Drug Research and Clinical Pharmacy, Xuzhou Medical University, 209 Tongshan Road, Xuzhou, Jiangsu 221004, P.R. China

E-mail: weiqunli@126.com

E-mail: gongyinhan@hotmail.com

${ }^{*}$ Co-first authors

Key words: sitagliptin, diabetic nephropathy, transforming growth factor- $\beta 1 /$ Smad signaling pathway, extracellular matrix, mesangial cells

\section{Introduction}

Diabetes is a severe disorder since it strongly increases the risk of cardiovascular complications, such as coronary artery disease, myocardial infarction, hypertension and dyslipidemia $(1,2)$. The cardiovascular injury mainly targets two important organs, eyes and kidneys (3). This has made diabetic nephropathy (DN) one of the most common complications for diabetic patients $(4,5)$. The main typical renal histological changes of DN are caused by the changes in the extracellular matrix (ECM). The ECM accumulation in DN results in mesangial expansion, tubulointerstitial fibrosis, and irreversible deterioration of renal function $(6,7)$.

It is reported that transforming growth factor- $\beta 1$ (TGF- $\beta 1$ ) plays an important role in the development of DN (8-10). After binding to its receptor, TGF- $\beta 1$ activates two critical downstream mediators, $\operatorname{Smad} 2$ and $\mathrm{Smad} 3$, to exert its biological activities such as ECM production, which is negatively regulated by Smad7, an inhibitor Smad. The effect of TGF- $\beta 1 /$ Smad3 signaling pathway on mediating renal fibrosis has been well recognized $(11,12)$, suggesting that the block of TGF- $\beta 1 / \mathrm{Smad} 3$ can provide an effective approach for preventing the progression of DN.

However, no proper effective treatment has been detected so far for retarding the progression of renal failure. Therefore, new therapeutic strategies in the management of DN are required (13).

Sitagliptin (SIT), a dipeptidyl peptidase-4 (DPP-4) inhibitor, exhibited a modest beneficial effect on glycated hemoglobin levels when used in combination with metformin for treatment of diabetes mellitus type 2 (14). Recent studies have shown that SIT alone can offer cardiovascular and neuropathic protections which are probably mediated through antioxidant, anti-inflammatory, and anti-apoptotic mechanisms (15-21). It is reported that SIT can also ameliorate renal ischemia reperfusion injury in rats (22). However, whether SIT has beneficial effect on prevention of DN remains unknown.

In this study the therapeutic effect of SIT for prevention of DN was systematically verified. Moreover, the possible mechanism through TGF- $\beta 1 /$ Smad signaling was investigated for the first time. 


\section{Materials and methods}

Ethics statements. This study was carried out in strict accordance with the recommendations in the Guiding Principles for Care and Use of Laboratory Animals of Xuzhou Medical University. The protocol was approved by the Committee on the Ethics of Laboratory Animals of Xuzhou Medical University (Xuzhou, China). All surgery was performed under sodium pentobarbital anesthesia, and all efforts were made to minimize suffering.

Animal experiments Male Sprague-Dawley rats (certificate no. SYXK2010-0011), weighing 180-200 g were obtained from the Laboratory Animal Center of Xuzhou Medical University (Xuzhou, China). The animals were housed in standard metabolic cages and maintained under standard condition at constant room temperature of $20-25^{\circ} \mathrm{C}$ and humidity of $40-70 \%$ with a 12:12 h light and dark cycle. All rats had free access to commercial regular chow and water for one week before the dietary manipulation. After one week's adaptation, fasting blood glucose (FBG) values were measured by OneTouch II blood glucose meter with overnight fasting. Thirty rats were randomly divided into two groups: control group and study group. The control group was fed with regular chow and the study group was given a high fat diet (HFD) and high calorie diet (36.3\% fat, $45 \%$ carbohydrate and $18.7 \%$ protein) for four weeks. Thereafter the values of FBG were calculated after $12 \mathrm{~h}$ fasting. The study group rats were initially injected intraperitoneally (i.p.) with streptozotocin (Sigma, St. Louis, MO, USA) at a low dose of $30 \mathrm{mg} / \mathrm{kg}$ diluted in citrate buffer ( $\mathrm{pH} 4.4)(23-25)$, while the negative control ones (NC group) were injected with citrate buffer. One week later, the study group rats with an FBG $<7.8 \mathrm{mmol} / 1$ were injected with repeated low dose of STZ (30 mg/kg). After four weeks of STZ injection, the study group rats with an FBG of $\geq 7.8 \mathrm{mmol} / \mathrm{l}$ twice or with random of $\geq 11.1 \mathrm{mmol} / 1$ were considered as type 2 diabetic rats (26). The type 2 diabetic rats were randomly divided into 2 groups: DN group $(n=9)$ was treated daily with normal saline solution and SIT group $(n=8)$ was administrated with SIT (Meck Sharp and Dohme Pty Ltd., Macquarie Park, NSW, Australia) at dose of $10 \mathrm{mg} / \mathrm{kg}$ (27). The same volume of normal saline solution was administered to the negative control group (NC group, $n=9$ ). The study period lasted 12 weeks.

Sample collection. After 12 weeks of treatment, the urine and blood samples were collected from the rats. After the animals were sacrificed, their kidneys were removed and weighed. The fresh kidney cortices were stored in formaldehyde solution for measurements. The kidney was fixed in $4 \%$ paraformaldehyde and the rest kidney tissues were snap frozen in liquid nitrogen and then stored at $-80^{\circ} \mathrm{C}$ for later analysis.

Biochemical analysis. The values of urine protein were determined by using urinary protein kits from NanJing JianCheng Bioengineering Institute (Nanjing, China). The values of creatinine and blood urea nitrogen (BUN) were determined by enzyme-linked immunosorbent assay (ELISA) kits from Wuhan ColorfulGene Biological Technology Co., Ltd. (Wuhan, China). The kidney index was calculated by ratio of kidney weight $(\mathrm{g}) /$ body weight $(\mathrm{kg})$.
Renal histological examination. After being fixed in $4 \%$ paraformaldehyde and embedded in paraffin, the kidney tissues were cut into 4- $\mu \mathrm{m}$ sections and stained with hematoxylin and eosin (H\&E), periodic acid schiff (PAS), and Masson staining as previously described (28). Briefly, for Masson staining, the 4- $\mu \mathrm{m}$ section samples were firstly deparaffinized in water and then stained with Masson composite staining solution for 5 min, washed successively with $0.2 \%$ acetic acid solution, $5 \%$ phosphotungstic acid, $0.2 \%$ acetic acid solution, and finally stained with bright green staining solution for $5 \mathrm{~min}$, washed twice with $0.2 \%$ acetic acid solution, dehydrated in absolute alcohol, put in xylene for transparency, and mounted with neutral gum. After this staining procedure, the collagen fibers were bluish green in color.

Immunohistochemistry examination. The immunohistochemistry analysis was performed according to the procedure reported previously (29). After the deparaffinization and hydration procedure, the 4- $\mu \mathrm{m}$ section samples were then washed with Tris-buffered saline (TBS; $10 \mathrm{mmol} / \mathrm{l}$ Tris $\mathrm{HCl}$, $0.85 \% \mathrm{NaCl}, \mathrm{pH} 7.2$ ). Endogenous peroxidase activity was quenched by incubating the section samples in $3 \% \mathrm{H}_{2} \mathrm{O}_{2}$ deionized water. After overnight incubation with rabbit polyclonal anti-collagen IV antibody and rabbit monoclonal anti-fibronectin antibody (both from Abcam, Cambridge, MA, USA) at $4^{\circ} \mathrm{C}$, the section samples were washed with TBS. Polymer helper was then added into the samples, and the section samples were incubated at room temperature for another $10 \mathrm{~min}$. The slides were thereafter washed with TBS, incubated with poly-HRP anti-rabbit IgG at room temperature for final $10 \mathrm{~min}$. A negative control without primary antibody was included in the experiment to verify antibody specificity. Finally, the sections were counterstained with 3,3'-diaminobenzidine (DAB) for $2 \mathrm{~min}$. Brownish yellow granular or linear deposits were interpreted as positive areas. Accumulation of collagen IV and fibronectin was determined using the quantitative Image Analysis system. After ten random fields in both glomeruli and tubulointerstitium under light microscopy (x400) were outlined and positive staining patterns were identified, the percentage of positive area in the examined field was then determined. The arterial lumen space was excluded from the study. Data were expressed as percentage of positive area examined.

Reverse transcription-polymerase chain reaction (RT-PCR). A RT-PCR procedure was performed to determine the relative mRNA quantities of TGF- $\beta 1$ and Smad7. Total RNA was extracted from rat kidney cortices by using TRIzol reagent (Tiangen, Beijing, China) according to the manufacturer's instructions. The obtained total RNA was converted into cDNA using the TIANScript RT kit (Tiangen). The upsteam and downstrean primers (Shanghai Sangon Co., Shanghai, China) of these genes are shown in Table I. Levels of mRNA expression were subjected to housekeeping gene $\beta$-actin.

Western blotting. As described in previous studies (30), renal cortical tissues were rapidly dissected and homogenized in lysis buffer containing protease inhibitor cocktail (MedChem Express, Princeton, NJ, USA). After centrifugation at $12,000 \mathrm{x} g$ for $10 \mathrm{~min}$, total protein was collected. The protein 
Table I. Primer sequences for RT-PCR.

\begin{tabular}{lll}
\hline Gene names & Forward sequences & Reverse sequences \\
\hline TGF- $\beta 1$ & 5'-ATGTGCAGGATAATTGCTGCC-3' & 5'-TGGTGTTGTACAGGCTGAGG-3' \\
Smad7 & 5'-TGGTGCGTGGTGGCATACTGG-3' & 5'-GACTCTTGTTGTCCGAATTGAGCT-3' \\
$\beta$-actin & 5'-TCAGGTCATCACTATCGGCAAT-3' & 5'-AAAGAAAGGGTGTAAAACGCA-3' \\
\hline
\end{tabular}

TGF- $\beta 1$, transforming growth factor- $\beta 1$; RT-PCR, reverse transcription-polymerase chain reaction.

A

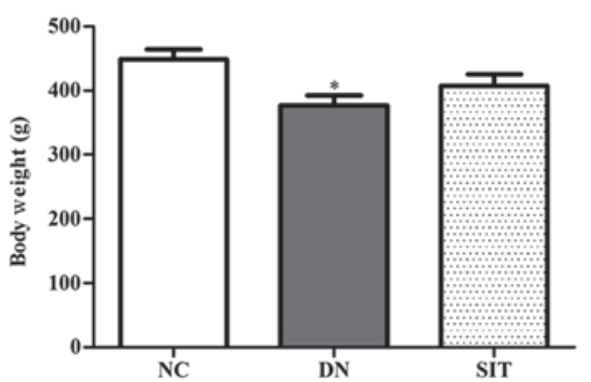

D

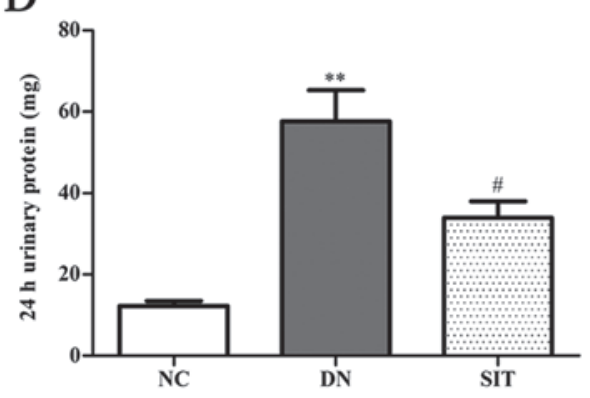

B

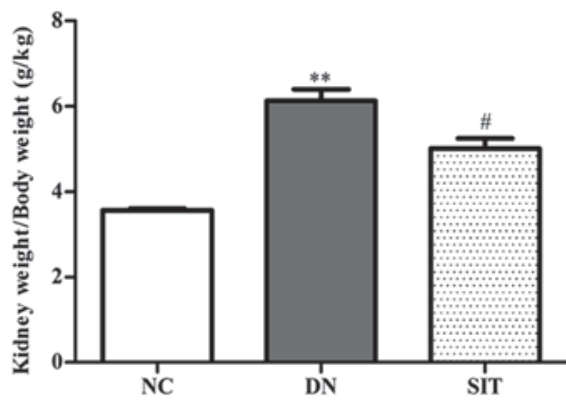

E

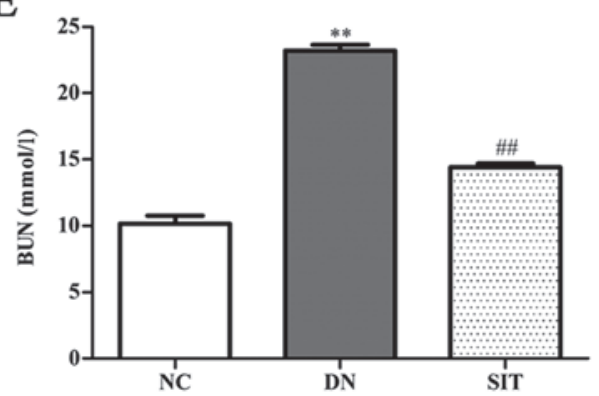

C

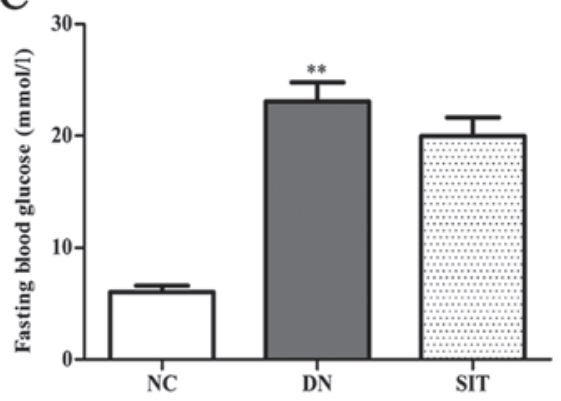

F

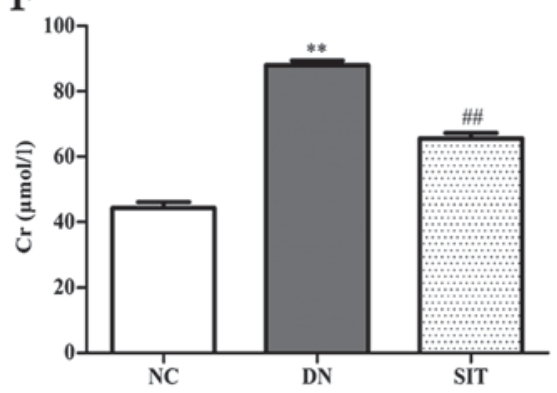

Figure 1. Sitagliptin (SIT) improves renal function. (A) Body weight. (B) Kidney weight/body weight; (C) Fasting blood glucose; (D) 24 h urinary protein; (E) blood urea nitrogen (BUN); (F) Cr. NC, negative control group; DN, diabetic nephropathy group; SIT, administration of SIT at dose of 10 mg/kg. Data are expressed as mean \pm SE. $n=6$. ${ }^{*} \mathrm{P}<0.05$ vs. NC group; ${ }^{* *} \mathrm{P}<0.01$ vs. NC group; ${ }^{\#} \mathrm{P}<0.05$ vs. DN group; ${ }^{\# \prime} \mathrm{P}<0.01$ vs. $\mathrm{DN}$ group.

concentration was determined by using the BCA protein assay kit (Beyotime Institute of Biotechnology, Shanghai, China) following the manufacturer's protocol. The protein samples were then mixed with sodium dodecyl sulfate-polyacrylamide gel electrophoresis (SDS-PAGE) loading buffer (Beyotime Institute of Biotechnology) and boiled for $10 \mathrm{~min}$. The protein samples were separated by $10 \%$ SDS polyacrylamide gel, and then transferred to nitrocellulose membranes. The transferred membranes were then blocked with blocking buffer (Beyotime Institute of Biotechnology) for $1 \mathrm{~h}$ at room temperature. Transferred membranes were incubated at $4^{\circ} \mathrm{C}$ overnight with rabbit polyclonal anti-TGF- $\beta 1$ antibody, rabbit monoclonal anti-Smad3 antibody, rabbit monoclonal anti-pSmad3 antibody, rabbit monoclonal anti-Smad7 antibody, rabbit monoclonal anti-GAPDH antibody (all from Abcam). The antigen-antibody complexes were washed three times for 5 min each and incubated with IRDye ${ }^{\circledR} 800 \mathrm{CW}$ goat anti-rabbit for $1 \mathrm{~h}$ at room temperature. After further three washes, the bands were added to infrared imaging system (Odyssey Sa; Li-COR, Lincoln, NE, USA). The intensity of TGF- $\beta 1$ and Smad7 were subjected to GAPDH protein analysis while Smad3 activation was assessed by the ratio of phosphorylated form among its corresponding total protein levels.

Cell experiments. Rat mesangial cells (MCs), cultured in Dulbecco's modified Eagle's medium, and were incubated at $37^{\circ} \mathrm{C}$ in a humidified atmosphere of $5 \% \mathrm{CO}_{2}$. During the experiments, the cells were first exposed to a normal concentration of glucose ( $\mathrm{NC}, 5.56 \mathrm{mmol} / \mathrm{l})$ for $24 \mathrm{~h}$, and then retreated with high glucose ( $\mathrm{HG}, 30 \mathrm{mmol} / 1$ glucose), high glucose with $0.1 \mu \mathrm{mol} / \mathrm{ml}$ sitagliptin (SITL), high glucose with $1 \mu \mathrm{mol} / \mathrm{ml}$ sitagliptin (SITM), and high glucose with $10 \mu \mathrm{mol} / \mathrm{ml}$ sitagliptin (SITH). Sitagliptin was dissolved in $1 \%$ (v/v) dimethyl sulfoxide (DMSO) and DMSO group was adopted as a control to rule out the effect of vehicle. Mannitol (MA) was adopted as a control to rule out the effect of osmotic pressure. The cells were harvested for analysis after $24 \mathrm{~h}$.

Immunofluorescence. MCs were seeded into 12 well-plates with glass bottom inserts. Then the normal glucose medium of the 12 well-plates was replaced with various concentrations 

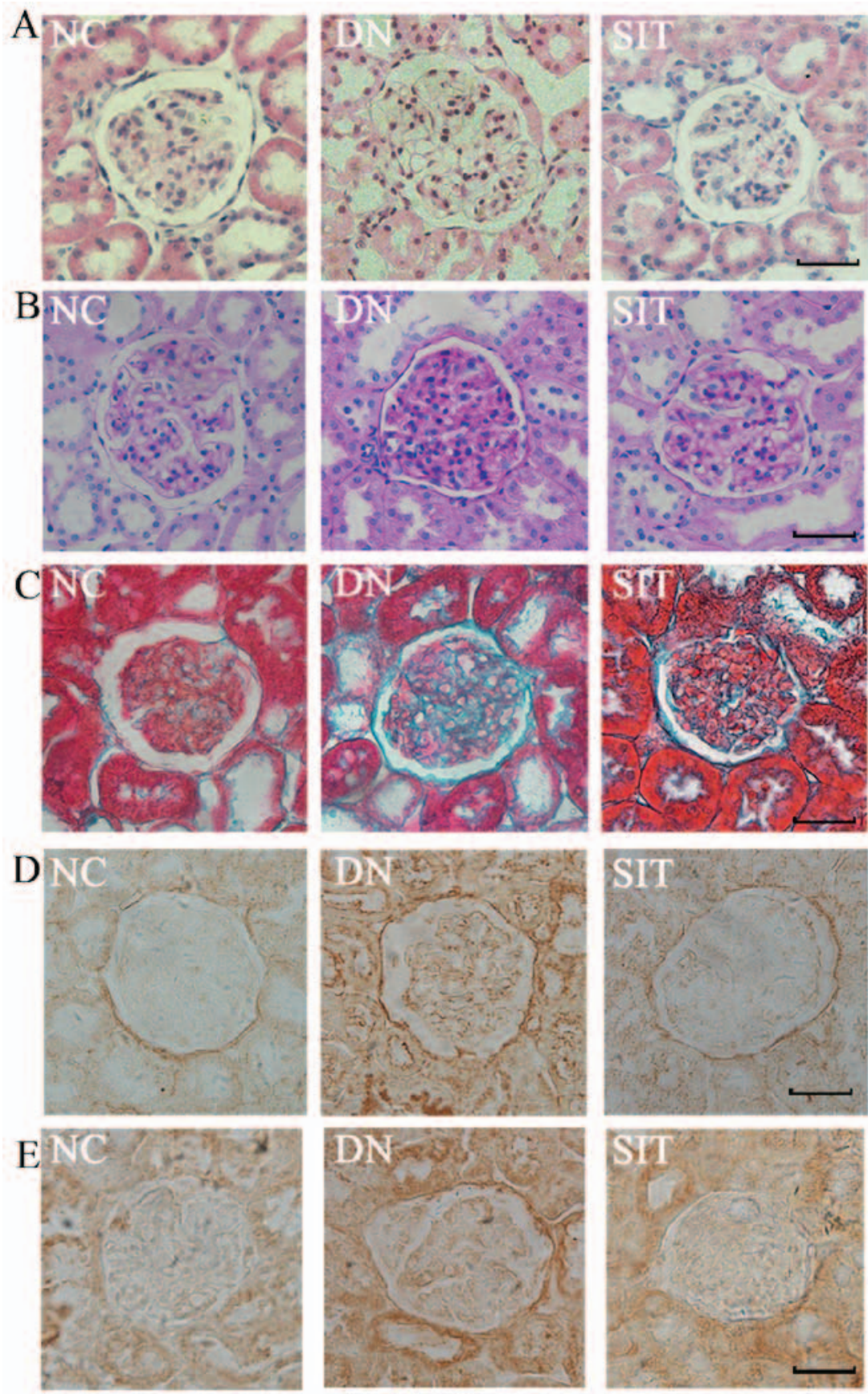

$\mathrm{F}$

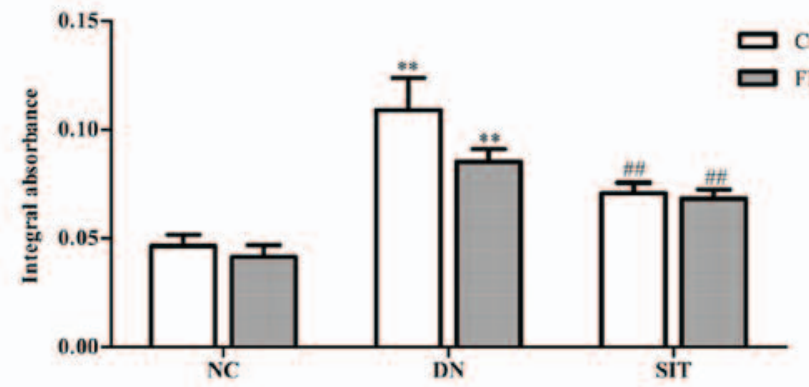

Figure 2. Renal histology and immunohistochemistry. (A) H\&E stained kidney sections of the normal control, diabetic nephropathy group, and diabetic nephropathy treated with sitagliptin (SIT). (B) Periodic acid-Schiff (PAS) staining was performed in the kidneys of the different groups. (C) Masson staining was performed in the kidneys of the different groups. (D) COLIV immunohistochemistry staining in the kidneys of the different groups. (E) FN immunohistochemistry staining in the kidneys of the different groups. (F) Integral absorbance of immunohistochemistry staining. NC, negative control group; DN, diabetic nephropathy group; SIT, administration of SIT at dose of $10 \mathrm{mg} / \mathrm{kg}$. $\mathrm{n}=3$. Bars, $50 \mu \mathrm{m} .{ }^{* *} \mathrm{P}<0.01 \mathrm{vs}$. NC group; ${ }^{\# \#} \mathrm{P}<0.01$ vs. DN group.

of sitagliptin or other controlling medium. After $24 \mathrm{~h}$, cells were washed with phosphate-buffered saline (PBS) and fixed with cold polysorbate for $15 \mathrm{~min}$ at room temperature. After being washed intensively three times with PBS, the 
A

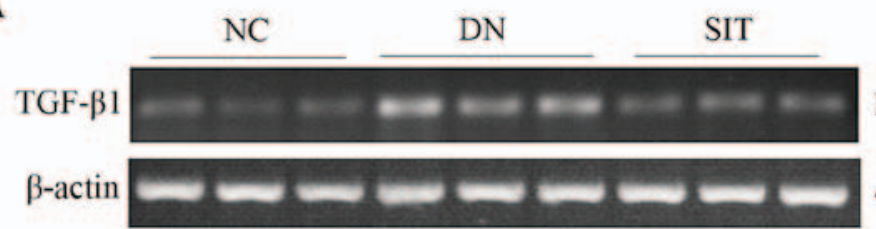
$182 \mathrm{bp}$ $432 \mathrm{bp}$

C
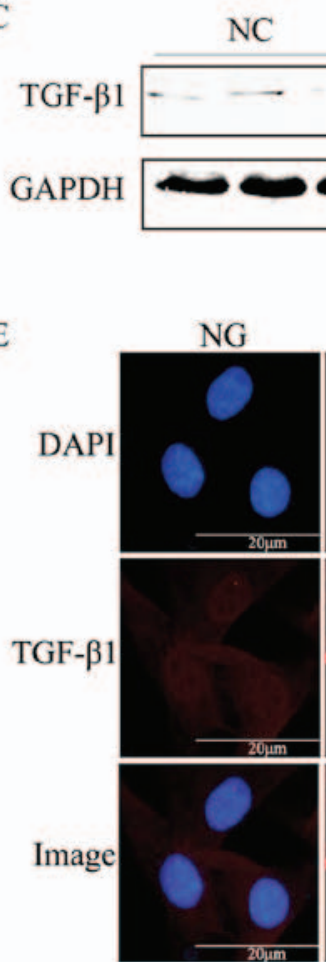

MA
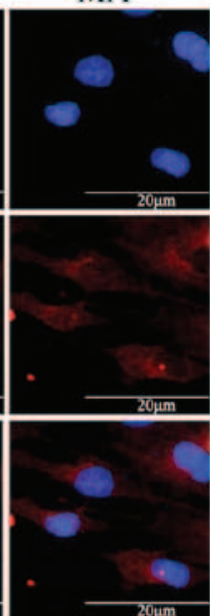

DN

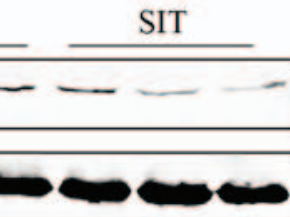
$44 \mathrm{kDa}$ $36 \mathrm{kDa}$
HG

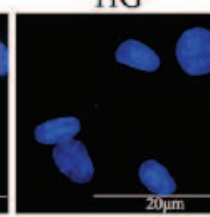

DMSO
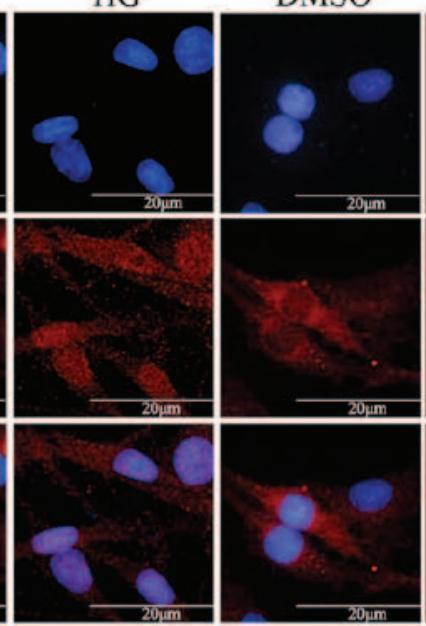

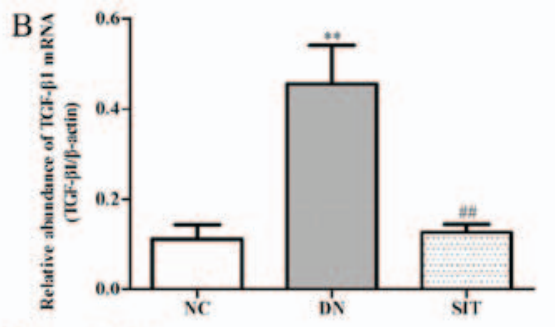

D

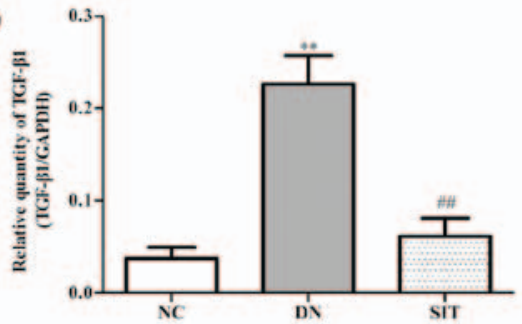

SITL
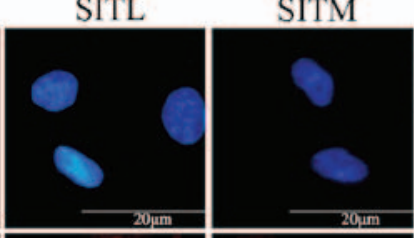

SITH
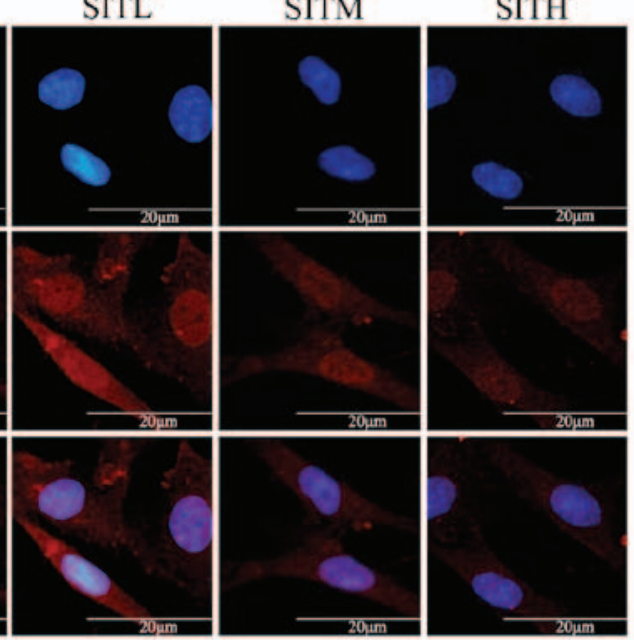

Figure 3. Effects of sitagliptin (SIT) on transforming growth factor- $\beta 1$ (TGF- $\beta 1$ ) expression in vivo and in vitro. (A) RT-PCR bands of TGF- $\beta 1 \mathrm{mRNA}$ in DN rats. (B) Relative abundance of TGF- $\beta 1 \mathrm{mRNA}$ in DN rats. (C) Western blot bands of TGF- $\beta 1$ in DN rats. (D) Relative abundance of TGF- $\beta 1$ in DN rats. (E) Expression of TGF- $\beta 1$ in mesangial cells induced by high glucose through immunofluorescence. NC, negative control group; DN, diabetic nephropathy group; SIT, administration of SIT at dose of $10 \mathrm{mg} / \mathrm{kg}$; NG, cells treated with normal glucose $5.56 \mathrm{mmol} / \mathrm{l}$; MA, cells treated with normal glucose $5.56 \mathrm{mmol} / \mathrm{l}$ + mannitol $24.44 \mathrm{mmol} / 1 ; \mathrm{HG}$, cells treated with high glucose $30 \mathrm{mmol} / 1$; dimethyl sulfoxide (DMSO), cells treated with high glucose + 1\%o DMSO; SITL, SITM, SITH, cells treated with high glucose $+0.1,1$ and $10 \mu \mathrm{mol} / \mathrm{ml}$ sitagliptin, respectively. Data are expressed as mean $\pm \mathrm{SE} . \mathrm{n}=3$. ${ }^{* *} \mathrm{P}<0.01 \mathrm{vs}$. NC group; ${ }^{\# / P}<0.01$ vs. DN group.

cells were added with $0.1 \%$ Triton X-100 in PBS for 15 min and blocked with 5\% BSA in PBS buffer for 30 min at room temperature, and incubated with TGF- $\beta 1$ and $\mathrm{p}-\mathrm{Smad} 3$ antibodies at $4^{\circ} \mathrm{C}$ overnight. The cells were then incubated with DyLight 594 AffiniPure Donkey anti-rabbit IgG $(\mathrm{H}+\mathrm{L}) 1 \mathrm{~h}$ at room temperature. The nuclei were counter-stained by 4,6-diamidino-2 phenylindole (DAPI) for $2 \mathrm{~min}$, then washed again with PBS two times before mounting with fluorescence mounting medium. Images were captured by Olympus BX43F fluorescence microscope (Olympus, Tokyo, Japan).

Enzyme-linked immunosorbent assay. The levels of Smad7 protein in the MCs were determined by ELISA (R.B. Scientific, Waltham, MA, USA). The levels of Smad7 was determined according to the manufacturer's instructions. The colorimetric reaction was measured at $450 \mathrm{~nm}$.

Statistical analysis. Data were expressed as means \pm SE. Statistical analyses were performed using the paired t-test for two data comparison and one-way analysis of variance (ANOVA) for multiple data comparison. A value of $\mathrm{P}<0.05$ was considered statistically significant.

\section{Results}

Biochemical analysis. As shown in Fig. 1, the kidney index and levels of FBG, $24 \mathrm{~h}$ urinary protein, $\mathrm{BUN}$ and $\mathrm{Cr}$ for the $\mathrm{DN}$ group were significantly higher than those of the NC group $(\mathrm{P}<0.01)$, suggesting that our early $\mathrm{DN}$ model was successful. The SIT group showed remarkably reduced kidney index and levels of $24 \mathrm{~h}$ urinary protein $(\mathrm{P}<0.05), \mathrm{BUN}(\mathrm{P}<0.01)$, and $\mathrm{Cr}$ $(\mathrm{P}<0.01)$, suggesting that SIT can improve the function of DN.

Histological and immunohistochemistry analysis. The H\&E staining (Fig. 2A) and PAS staining (Fig. 2B) of the kidney sections from the control group revealed a normal glomerulus surrounded by Bowman's capsule and proximal and distal convoluted tubules without any inflammatory changes. The DN 
A
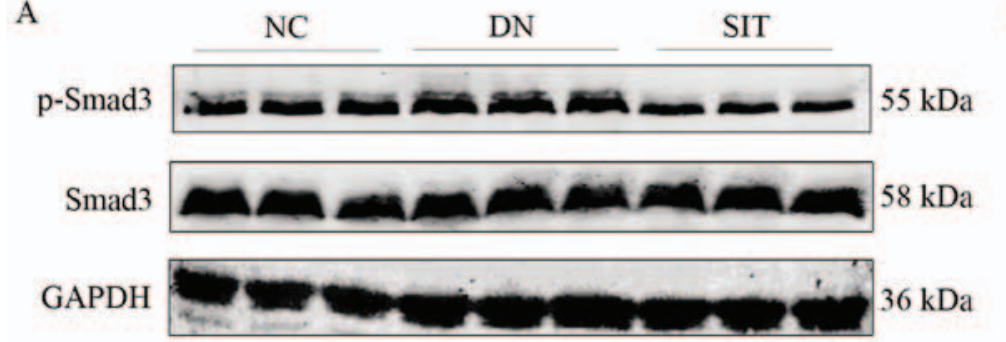

C

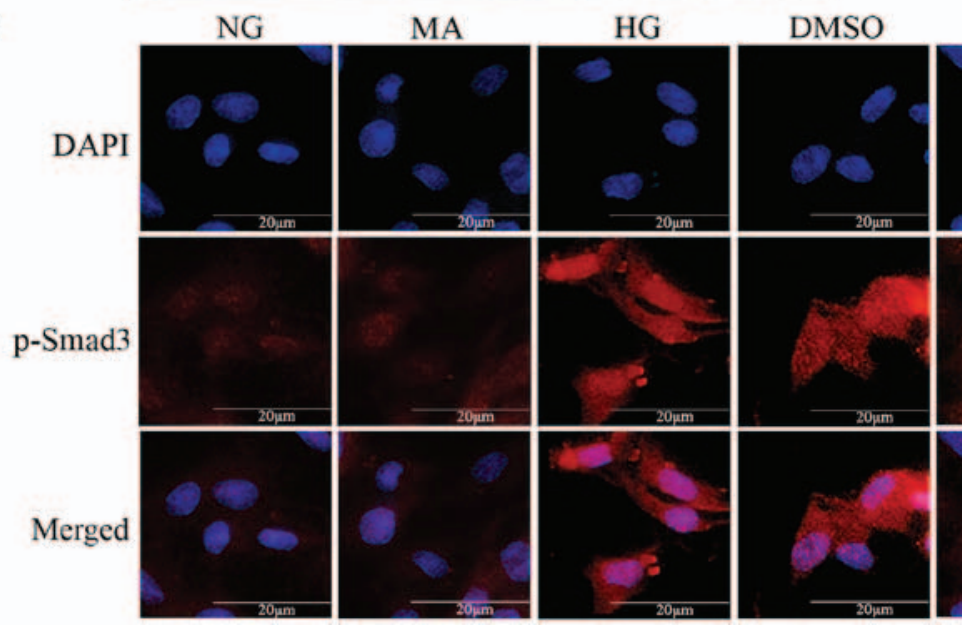

B

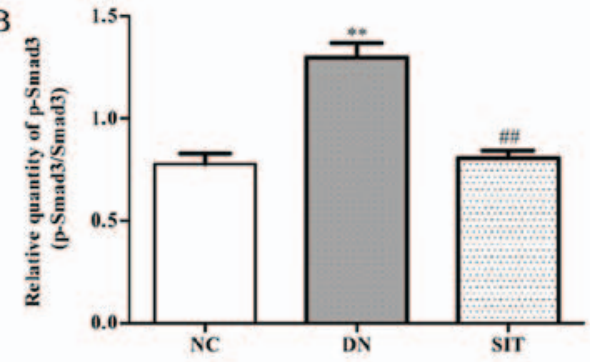

SITL
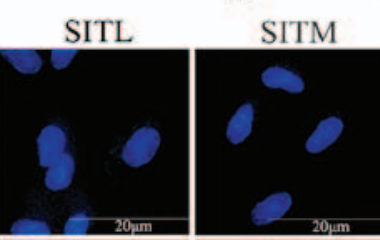

SITH
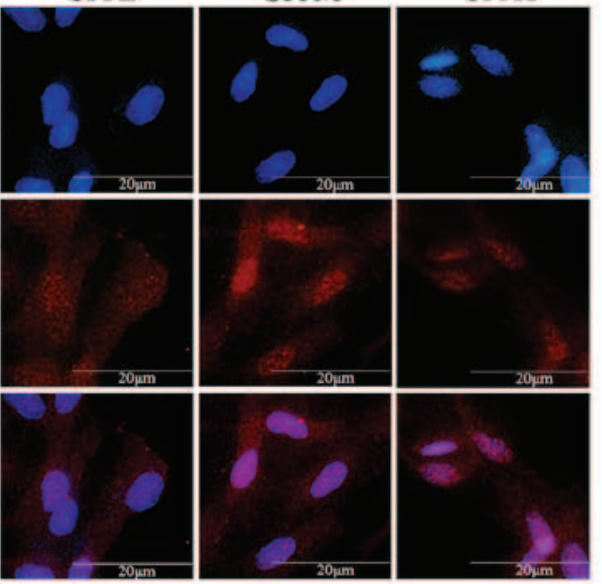

Figure 4. Effects of sitagliptin (SIT) on p-Smad3 expression in vivo and in vitro. (A) Western blot bands of p-Smad3 in DN rats. (B) Relative abundance of p-Smad3 in DN rats. (C) Expression of p-Smad3 in mesangial cells induced by high glucose through immunofluorescence. NC, negative control group; DN, diabetic nephropathy group; SIT, administration of SIT at dose of $10 \mathrm{mg} / \mathrm{kg}$; NG, cells treated with normal glucose $5.56 \mathrm{mmol} / \mathrm{l}$; MA, cells treated with normal glucose $5.56 \mathrm{mmol} / 1+$ mannitol $24.44 \mathrm{mmol} / \mathrm{l}$; HG, cells treated with high glucose $30 \mathrm{mmol} / \mathrm{l}$; dimethyl sulfoxide (DMSO), cells treated with high glucose $+1 \%$ DMSO; SITL, SITM, SITH, cells treated with high glucose $+0.1,1$ and $10 \mu \mathrm{mol} / \mathrm{ml}$ sitagliptin, respectively. Data are expressed as mean \pm SE $\mathrm{n}=3$. ${ }^{* *} \mathrm{P}<0.01$ vs. NC group; ${ }^{\# \#} \mathrm{P}<0.01$ vs. DN group.

group showed renal tubule atrophy, thickening of the basement membrane. The SIT group exhibited a significantly-attenuated basementmembrane. Compared with control group, the DN group exhibited a maximum accumulation of collagen IV (Col IV) and fibronectin $(\mathrm{FN})$ in the renal cortex revealed by Masson staining (Fig. 2C) and immunohistochemistry (Fig. 2D-E). Compared with the DN group, significantly-reduced renal fibrosis was observed in the SIT-treated group. All of these fibrotic changes in the diabetic kidney were largely attenuated by treatment with SIT as indicated in Fig. $2 \mathrm{~F}(\mathrm{P}<0.01)$.

Effects of sitagliptin on TGF- $\beta 1$ expression in DN rats and high glucose-induced MCs. As illustrated in Fig. 3A-D, the DN group exhibited remarkably higher level of TGF- $\beta 1$ mRNA and TGF- $\beta 1$ when compared to the NC group $(\mathrm{P}<0.01)$. Interestingly, SIT-treated group showed significantly lower level of TGF- $\beta 1$ mRNA and TGF- $\beta 1$ than DN group $(\mathrm{P}<0.01)$. The above indicates that the increased TGF- $\beta 1$ expression was observed in DN rats through both western blotting and PCR as well as in high glucose-induced MCs by immunofluorescence. SIT-treated groups reduced the increased TGF- $\beta 1$ expression (Fig. 3E). Taken together, these results suppport that treatment with SIT reverses the overexpression of TGF- $\beta 1$.

Effects of sitagliptin on $p$-Smad3 expression in DN rats and high glucose-induced MCs. In Fig. 4A and B, relative quantity of $\mathrm{p}$-Smad3 was upregulated in DN group when compared to the NC group $(\mathrm{P}<0.01)$. However, administration of SIT significantly decreased the expression of $\mathrm{p}-\mathrm{Smad} 3$ compared with DN group $(\mathrm{P}<0.01)$. In correlation with the finding from western blotting in DN rats, the p-Smad3 expression in MCs induced by high glucose was increased through immunofluorescence. However, SIT-treated groups could downregulate the increased p-Smad3 expression (Fig. 4C). Thus, the results indicated that administration of SIT significantly decreased the level of p-Smad3 in DN rats and MCs induced by high glucose.

Effects of sitagliptin on Smad7 expression in DN rats and high glucose-induced MCs. The DN group exhibited lower amount of inhibitory Smad7 than NC group $(\mathrm{P}<0.01)$. On the contrary, the SIT-treated group showed higher amount of inhibitory Smad7 than DN group ( $\mathrm{P}<0.05)$ (Fig. 5A-D). In MCs induced by high glucose the levels of Smad7 were remarkably downregulated compared to those of the NG group at $24 \mathrm{~h}$ through ELISA $(\mathrm{P}<0.01)$. The levels of Smad7 in SITL, SITM and SITH groups were significantly higher than those of the HG group $(\mathrm{P}<0.01)$. No significant difference was found between the MA group and the NG group in terms of the level of Smad7. The Smad7 level in DMSO group was almost identical to that of the HG group, indicating that no obvious effects were generated by the osmotic pressure and the vehicle. The above results indicated that administration of SIT significantly upgraded the levels of Smad7 in DN rats and MCs induced by high glucose.

\section{Discussion}

DN is one of the most important causes leading to endstage renal disease, which affects $15-25 \%$ of T1DM patients and 
A

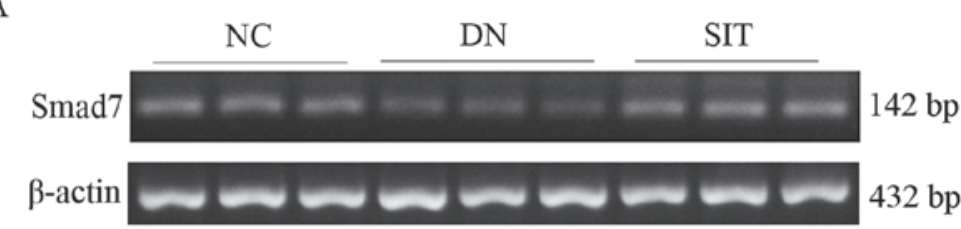

$\mathrm{C}$

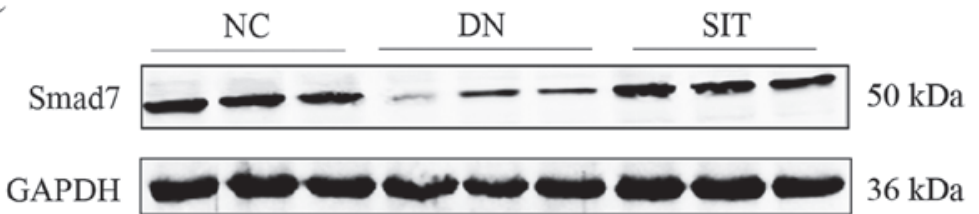

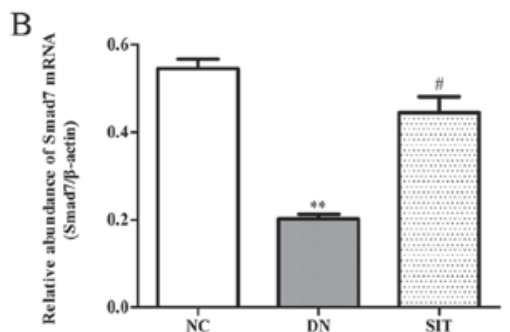

D

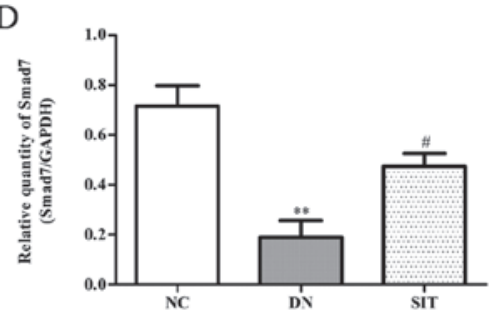

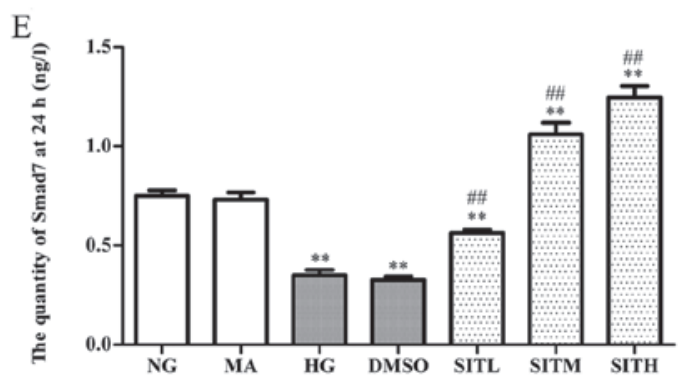

Figure 5. Effects of sitagliptin (SIT) on Smad7 expression in vivo and in vitro. (A) RT-PCR bands of Smad7 mRNA in DN rats. (B) Relative abundance of Smad7 mRNA in DN rats. (C) Western blot bands of Smad7 in DN rats. (D) Relative abundance of Smad7 in DN rats. (E) Expression of Smad7 in mesangial cells induced by high glucose through enzyme-linked immunosorbent assay (ELISA). NC, negative control group; DN, diabetic nephropathy group; SIT, administration of SIT at dose of $10 \mathrm{mg} / \mathrm{kg}$; NG, cells treated with normal glucose $5.56 \mathrm{mmol} / \mathrm{l}$; MA, cells treated with normal glucose $5.56 \mathrm{mmol} / \mathrm{l}+\mathrm{mannitol} 24.44 \mathrm{mmol} / \mathrm{l}$; HG, cells treated with high glucose $30 \mathrm{mmol} / \mathrm{l}$; dimethyl sulfoxide (DMSO), cells treated with high glucose + 1\%o DMSO; SITL, SITM, SITH, cells treated with high glucose $+0.1,1$ and $10 \mu \mathrm{mol} / \mathrm{ml}$ sitagliptin, respectively. Data are expressed as mean $\pm \mathrm{SE} . \mathrm{n}=3$. ${ }^{* *} \mathrm{P}<0.01$ vs. $\mathrm{NC}$ group; ${ }^{\# P} \mathrm{P}<0.05$ vs. $\mathrm{DN}$ group; ${ }^{\# \#} \mathrm{P}<0.01 \mathrm{vs}$. DN group.

$30-40 \%$ of type 2 diabetes mellitus (T2DM) patients (31,32). $\mathrm{DN}$, also known as nodular diabetic glomerulosclerosis, is characterised by mesangial cell proliferation and excessive accumulation of ECM, which may ultimately lead to chronic renal failure (33). The major ECM proteins such as collagen IV and fibronectin are often used as markers of fibrogenesis in various kidney fibrotic diseases including DN (34-36).

It is now well-known that TGF- $\beta 1 / \mathrm{Smad} 3$ mediates fibrosis $(11,12)$. In this study, we examined the therapeutic effect of SIT on DN using a rat model of T2DM and high glucoseinduced rat MCs. T2DM was induced in rats using a HFD plus repeated low dose STZ injections. Our data showed that the kidney index, the level of $24 \mathrm{~h}$ urinary protein, levels of BUN and $\mathrm{Cr}$ for the DN rats were significantly increased, indicating a successful renal dysfunction in T2DM rats. The increased intensity of PAS and Masson staining, ECM accumulation also suggested renal lesions in the T2DM rats. These results demonstrated that the T2DM rat model was well established and DN rats were successfully induced renal dysfunction (37). By treating the DN rats with SIT in our study, we found that the SIT significantly inhibited kidney fibrosis and remarkably decreased the levels of proteinuria, BUN and $\mathrm{Cr}$. This indicated that the SIT effectively improved the renal function.

An interesting finding of this study was that SIT works through inhibiting TGF- $\beta 1 / \mathrm{Smad} 3$ signaling and activating Smad7 expression to alleviate renal fibrosis of the diabetic kidney. It is well-known that both inhibition of TGF- $\beta 1 / \mathrm{Smad} 3$ pathway and the increasing Smad7 expression results in reducing ECM accumulation (12). Moreover, we also found that the induced DN from T2DM by HFD plus repeated low dose injections of STZ and high glucose-induced rat MCs were all associated with a marked activation of Smad3 but a loss of Smad7, suggesting imbalance between Smad3 and Smad7 signaling in the pathogenesis of DN model. In contrast, treatment with SIT weakened diabetic renal injury by rebalancing the TGF- $\beta 1 /$ Smad signaling pathway.

Thus, SIT exhibited potent therapeutic potential in preventing the progression of $\mathrm{DN}$ through blocking TGF- $\beta 1 /$ Smad3-mediated renal fibrosis and upregulating inhibitory Smad7, which may provide the basis of treatment for DN patients in the future.

\section{Acknowledgements}

Not applicable.

\section{Funding}

This study was funded by the National Innovative Practice Training Program for Students of Higher Education Institutions (no. 201410313024), the Innovative Practice Training Program for Students of Jiangsu Higher Education 
Institutions (no. 201410313024Z), the School of Pharmacy, Xuzhou Medical College Innovative Practice Training Program for Graduates (no. 2014YKYCX013), Young Medical Talents of Wuxi (no. QNRC020), and the Young Project of Wuxi Health and Family Planning Research (no. Q201706). This study was also funded by School of Pharmacy, Xuzhou Medical College Innovative Practice Training Program for Graduates (no. 2014YKYCX013).

\section{Availability of data and material}

The datasets used and/or analyzed during the current study are available from the corresponding author on reasonable request.

\section{Authors' contributions}

QW, YG, and DW conceived and designed the study. DW, GZ, $\mathrm{XC}, \mathrm{TW}, \mathrm{CL}$ and CC performed the experiments. DW and TW wrote the paper. CL and CC reviewed and edited the manuscript. All authors read and approved the final manuscript.

\section{Ethics approval and consent to participate}

Not applicable.

\section{Consent for publication}

Not applicable.

\section{Competing interests}

The authors declare that they have no competing interests.

\section{References}

1. Roberts KT: The potential of fenugreek (Trigonella foenumgraecum) as a functional food and nutraceutical and its effects on glycemia and lipidemia. J Med Food 14: 1485-1489, 2011.

2. Dixit P, Ghaskadbi S, Mohan H and Devasagayam TP: Antioxidant properties of germinated fenugreek seeds. Phytother Res 19: 977-983, 2005.

3. Kashihara N, Haruna Y, Kondeti VK and Kanwar YS: Oxidative stress in diabetic nephropathy. Curr Med Chem 17: 4256-4269, 2010.

4. Reutens AT and Atkins RC: Epidemiology of diabetic nephropathy. Contrib Nephrol 170: 1-7, 2011.

5. Collins AJ, Foley RN, Herzog C, Chavers B, Gilbertson D, Ishani A, Kasiske B, Liu J, Mau LW, McBean M, et al: US Renal Data System 2010 Annual Data Report. Am J Kidney Dis 57 (Suppl 1): A8, e1-e526, 2011.

6. Kolset SO, Reinholt FP and Jenssen T: Diabetic nephropathy and extracellular matrix. J Histochem Cytochem 60: 976-986, 2012.

7. Tervaert TW, Mooyaart AL, Amann K, Cohen AH, Cook HT, Drachenberg CB, Ferrario F, Fogo AB, Haas M, de Heer E, et al; Renal Pathology Society: Pathologic classification of diabetic nephropathy. J Am Soc Nephrol 21: 556-563, 2010.

8. Wang W, Huang XR, Li AG, Liu F, Li JH, Truong LD, Wang XJ and Lan HY: Signaling mechanism of TGF-betal in prevention of renal inflammation: Role of Smad7. J Am Soc Nephrol 16 : 1371-1383, 2005.

9. Belghith M, Bluestone JA, Barriot S, Mégret J, Bach JF and Chatenoud L: TGF-beta-dependent mechanisms mediate restoration of self-tolerance induced by antibodies to CD3 in overt autoimmune diabetes. Nat Med 9: 1202-1208, 2003.

10. Huang C, Kim Y, Caramori ML, Fish AJ, Rich SS, Miller ME, Russell GB and Mauer M: Cellular basis of diabetic nephropathy: II. The transforming growth factor-beta system and diabetic nephropathy lesions in type 1 diabetes. Diabetes 51: 3577-3581, 2002.
11. Oujo B, Muñoz-Félix JM, Arévalo M, Núñez-Gómez E, Pérez-Roque L, Pericacho M, González-Núñez M, Langa C, Martínez-Salgado C, Perez-Barriocanal F, et al: L-Endoglin overexpression increases renal fibrosis after unilateral ureteral obstruction. PLoS One 9: e110365, 2014.

12. Zhao M, Zheng S, Yang J, Wu Y, Ren Y, Kong X, Li W and Xuan J: Suppression of TGF- $\beta 1 /$ Smad signaling pathway by sesamin contributes to the attenuation of myocardial fibrosis in spontaneously hypertensive rats. PLoS One 10: e0121312, 2015.

13. Sato S, Kawamura H, Takemoto M, Maezawa Y, Fujimoto M, Shimoyama T, Koshizaka M, Tsurutani Y, Watanabe A, Ueda S, et al: Halofuginone prevents extracellular matrix deposition in diabetic nephropathy. Biochem Biophys Res Commun 379: 411-416, 2009.

14. Ballav C and Gough SC: Safety and efficacy of sitagliptinmetformin in fixed combination for the treatment of type 2 diabetes mellitus. Clin Med Insights Endocrinol Diabetes 6: 25-37, 2013

15. Nade VS, Kawale LA and Patel KM: Protective effect of sitagliptin and rosuvastatin combination on vascular endothelial dysfunction in type-2 diabetes. Indian J Pharm Sci 77: 96-102, 2015.

16. Brenner C, Kränkel N, Kühlenthal S, Israel L, Remm F, Fischer C, Herbach N, Speer T, Grabmaier U, Laskowski A, et al: Short-term inhibition of DPP-4 enhances endothelial regeneration after acute arterial injury via enhanced recruitment of circulating progenitor cells. Int J Cardiol 177: 266-275, 2014.

17. Tsai TH, Sun CK, Su CH, Sung PH, Chua S, Zhen YY, Leu S, Chang HW, Yang JL and Yip HK: Sitagliptin attenuated brain damage and cognitive impairment in mice with chronic cerebral hypo-perfusion through suppressing oxidative stress and inflammatory reaction. J Hypertens 33: 1001-1013, 2015.

18. El-Sahar AE, Safar MM, Zaki HF, Attia AS and Ain-Shoka AA: Sitagliptin attenuates transient cerebral ischemia/reperfusion injury in diabetic rats: Implication of the oxidative-inflammatoryapoptotic pathway. Life Sci 126: 81-86, 2015.

19. Bachor TP, Marquioni-Ramella MD and Suburo AM: Sitagliptin protects proliferation of neural progenitor cells in diabetic mice. Metab Brain Dis 30: 885-893, 2015.

20. Picatoste B, Ramírez E, Caro-Vadillo A, Iborra C, Ares-Carrasco S, Egido J, Tuñón J and Lorenzo O: Sitagliptin reduces cardiac apoptosis, hypertrophy and fibrosis primarily by insulin-dependent mechanisms in experimental type-II diabetes. Potential roles of GLP-1 isoforms. PLoS One 8: e78330, 2013.

21. Gault VA, Lennox R and Flatt PR: Sitagliptin, a dipeptidyl peptidase-4 inhibitor, improves recognition memory, oxidative stress and hippocampal neurogenesis and upregulates key genes involved in cognitive decline. Diabetes Obes Metab 17: 403-413, 2015.

22. Chang MW, Chen $\mathrm{CH}$, Chen YC, Wu YC, Zhen YY, Leu S, Tsai TH, Ko SF, Sung PH, Yang CC, et al: Sitagliptin protects rat kidneys from acute ischemia-reperfusion injury via upregulation of GLP-1 and GLP-1 receptors. Acta Pharmacol Sin 36: 119-130, 2015.

23. Sheela N, Jose MA, Sathyamurthy D and Kumar BN: Effect of silymarin on streptozotocin-nicotinamide-induced type 2 diabetic nephropathy in rats. Iran J Kidney Dis 7: 117-123, 2013.

24. Hou J, Zheng D, Zhong G and Hu Y: Mangiferin mitigates diabetic cardiomyopathy in streptozotocin-diabetic rats. Can J Physiol Pharmacol 91: 759-763, 2013.

25. Epp RA, Susser SE, Morissette MP, Kehler DS, Jassal DS and Duhamel TA: Exercise training prevents the development of cardiac dysfunction in the low-dose streptozotocin diabetic rats fed a high-fat diet. Can J Physiol Pharmacol 91: 80-89, 2013.

26. Zhang M, Lv XY, Li J, Xu ZG and Chen L: The characterization of high-fat diet and multiple low-dose streptozotocin induced type 2 diabetes rat model. Exp Diabetes Res 2008: 704045, 2008.

27. Mega C, de Lemos ET, Vala H, Fernades R, Oliveira J, Mascarenhas-Melo F, Teixeira F, Reis F: Diabetic nephropathy amelioration by a low-dose sitagliptin in an animal model of type 2 diabetes (Zucker diabetic fatty rat). Exp Diabetes Res 2011: 162092, 2011.

28. Li WG, Chen YL, Chen JX, Qu L, Xue BD, Peng ZH and Huang ZQ: Portal venous arterialization resulting in increased portal inflow and portal vein wall thickness in rats. World $\mathrm{J}$ Gastroenterol 14: 6681-6688, 2008.

29. Arumugam S, Thandavarayan RA, Veeraveedu PT, Nakamura T, Arozal W, Sari FR, Giridharan VV, Soetikno V, Palaniyandi SS, Harima M, et al: Beneficial effects of edaravone, a novel antioxidant, in rats with dilated cardiomyopathy. J Cell Mol Med 16: 2176-2185, 2012. 
30. Wang M, Zhou W, Zhou X, Zhuang F, Chen Q, Li M, Ma T and Gu S: Antidepressant-like effects of alarin produced by activation of TrkB receptor signaling pathways in chronic stress mice. Behav Brain Res 280: 128-140, 2015.

31. Brownlee M: The pathobiology of diabetic complications: A unifying mechanism. Diabetes 54: 1615-1625, 2005.

32. Shaw JE, Sicree RA and Zimmet PZ: Global estimates of the prevalence of diabetes for 2010 and 2030. Diabetes Res Clin Pract 87: 4-14, 2010

33. Kanwar YS, Wada J, Sun L, Xie P, Wallner EI, Chen S, Chugh S and Danesh FR: Diabetic nephropathy: Mechanisms of renal disease progression. Exp Biol Med (Maywood) 233: 4-11, 2008.

34. Wang JY, Yin XX, Wu YM, Tang DQ, Gao YY, Wan MR, Hou XY and Zhang B: Ginkgo biloba extract suppresses hypertrophy and extracellular matrix accumulation in rat mesangial cells. Acta Pharmacol Sin 27: 1222-1230, 2006.

35. Gonzalez J, Klein J, Chauhan SD, Neau E, Calise D, Nevoit C, Chaaya R, Miravete M, Delage C, Bascands JL, et al: Delayed treatment with plasminogen activator inhibitor-1 decoys reduces tubulointerstitial fibrosis. Exp Biol Med (Maywood) 234 1511-1518, 2009.
36. Xu W, Shao X, Tian L, Gu L, Zhang M, Wang Q, Wu B, Wang L, Yao J, Xu X, et al: Astragaloside IV ameliorates renal fibrosis via the inhibition of mitogen-activated protein kinases and antiapoptosis in vivo and in vitro. J Pharmacol Exp Ther 350: 552-562, 2014

37. Li L, Yin Q, Tang X, Bai L, Zhang J, Gou S, Zhu H, Cheng J, Fu P and Liu F: C3a receptor antagonist ameliorates inflammatory and fibrotic signals in type 2 diabetic nephropathy by suppressing the activation of TGF- $\beta / \mathrm{smad} 3$ and IKB $\alpha$ pathway. PLoS One 9: e113639, 2014.

This work is licensed under a Creative Commons Attribution-NonCommercial-NoDerivatives 4.0 International (CC BY-NC-ND 4.0) License. 